\title{
TOPOGRAPHIC MAPPING
}

OLOCICAL SU

S. W A HINGTON
JUN2 91966

L LIBPAF? 


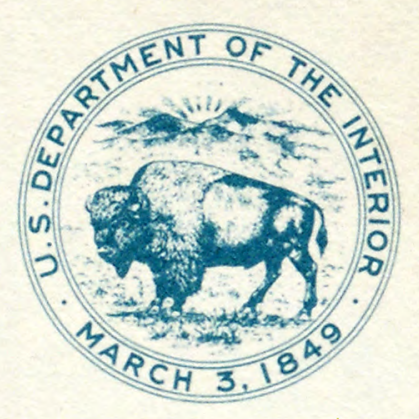

\title{
UNITED STATES DEPARTMENT OF THE INTERIOR
}

\author{
GEOLOGICAL SURVEY
}

USGS. TOPOGRAPHIC DIVISION. 


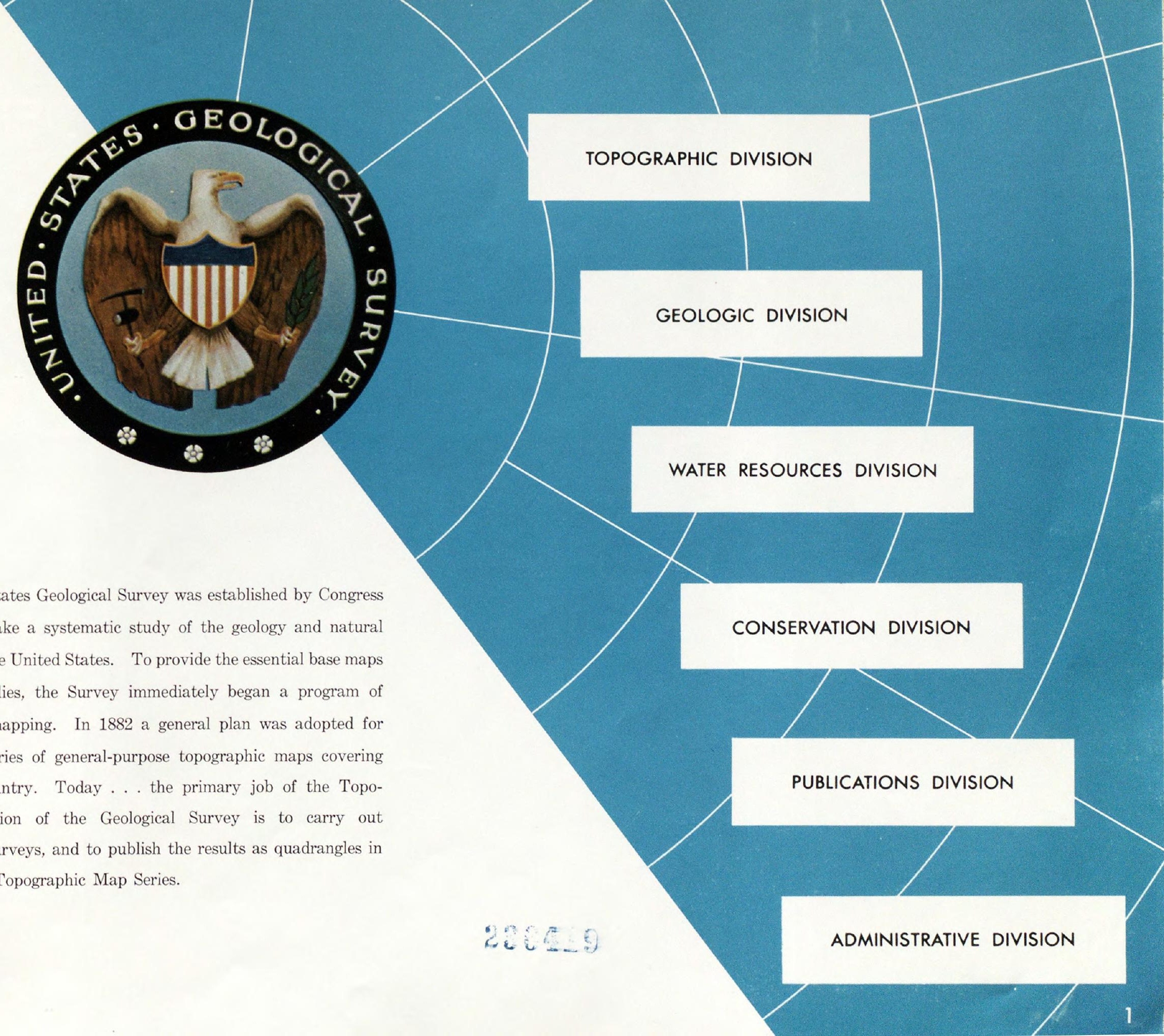






"Space will yield many things to man in the coming decade . . . He will use space as an observation post. Camera-equipped satellites will map the earth and keep track of ships, spot icebergs, locate vessels in distress, and make other aerial observations."

National Aeronautics and Space Administration 


\section{SCIENTIFIC MEDIUM}

\section{TOPOGRAPHIC MAPS}

In this new age of orbiting satellites the earth is a base for exploring space-literally, a jumpingoff place. But even with his head in the stars, man's feet must be on the ground. For success in space, exact knowledge is needed of the size, shape, and configuration of the earth. This knowledge is gained from geodetic and topographic surveys, and presented in the form of topographic maps.

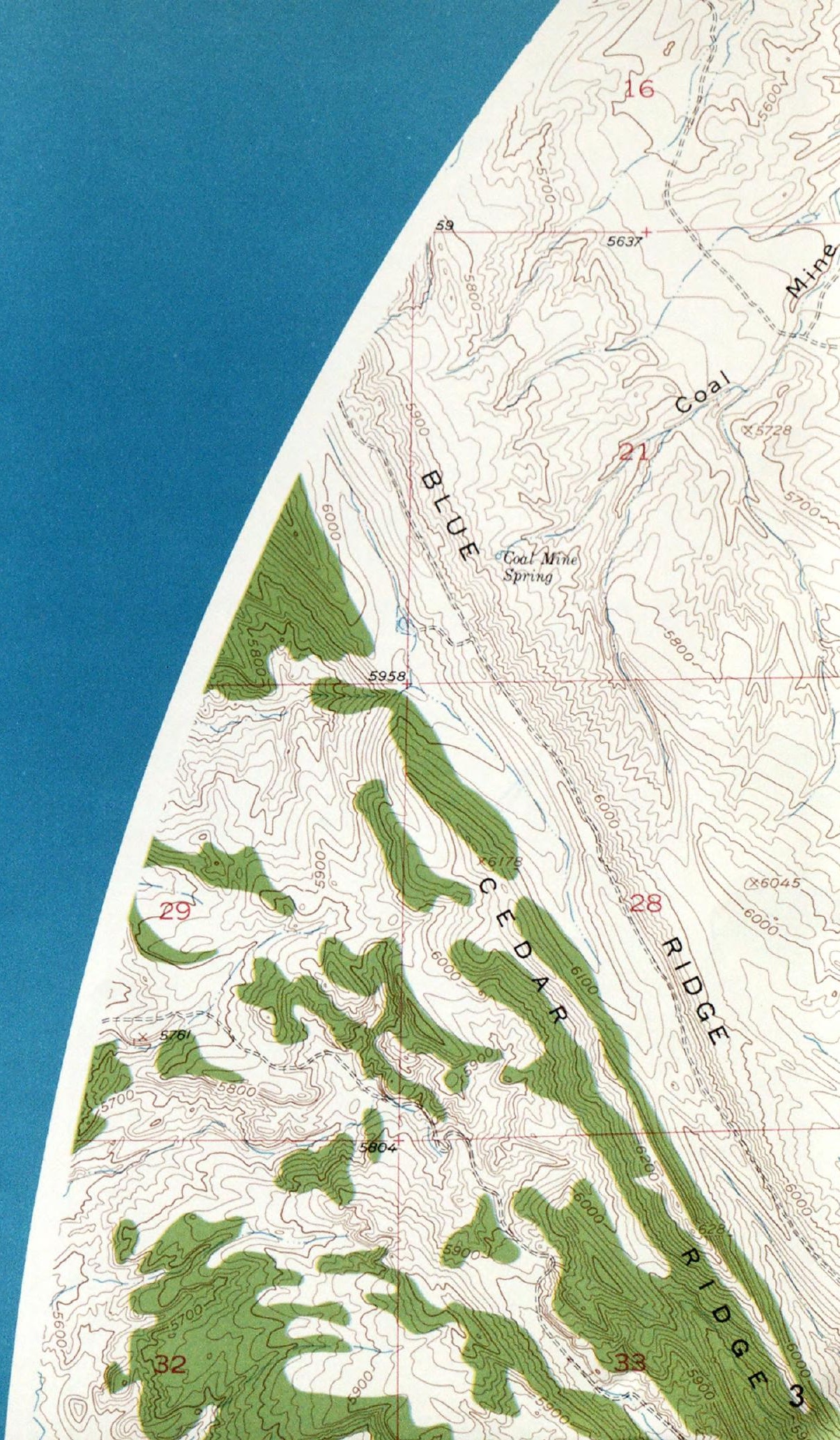




\section{AN INVENTORY OF PHYSICAL RESOURCES}



Topographic maps present a detailed record of survey of a land area, with the geographic positions and elevations of natural and manmade features. By means of contours and other symbols, topographic maps show the shape of the land-the mountains, valleys, and plains-in measurable form. They show the network of streams and rivers and other water features in their true relationship to the land, and the principal works of man in their relative size and actual position. In a sense, topographic maps are an inventory of the physical features of and on the land surface. They are a historical record of man's achievements and a modern blueprint for planning the future. 


\section{The Geological Survey In The Mapping Task}

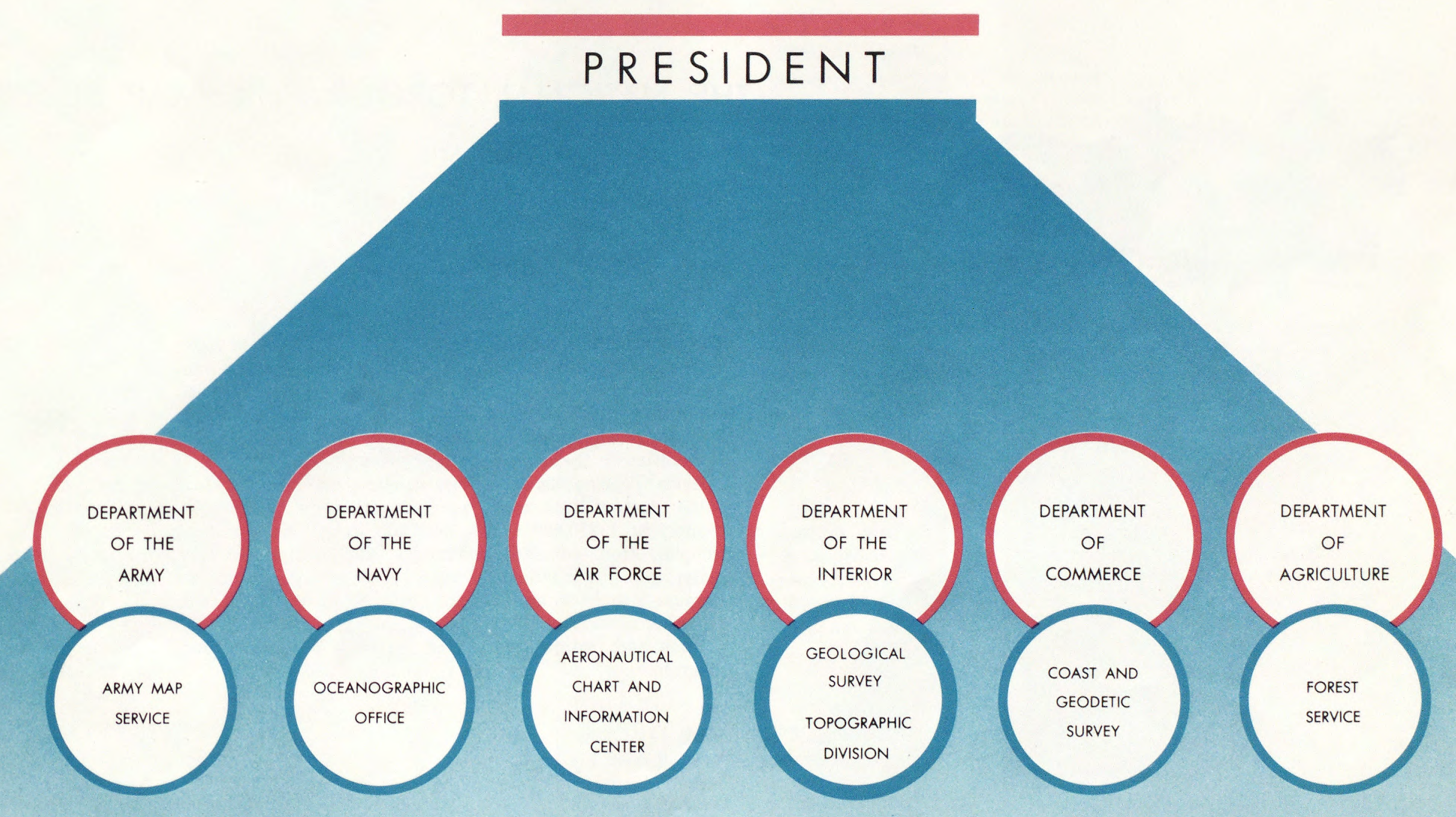




\section{MAPPING}

\section{ACTIVITIES}

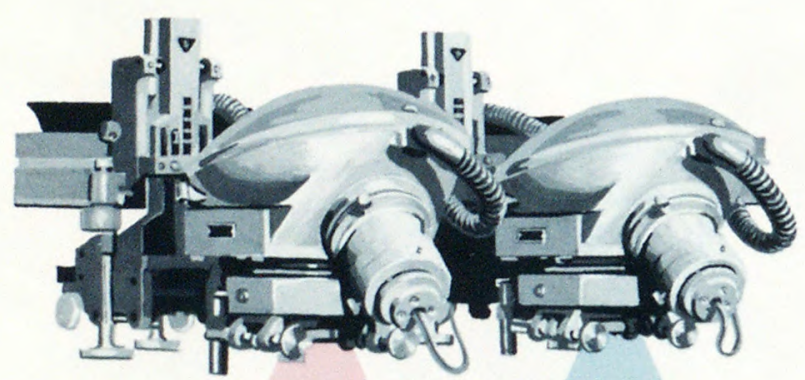

\section{THE NATIONAL TOPOGRAPHIC MAP SERIES}

The general-purpose maps prepared by the Topographic Division are published in a number of different series, known collectively as the National Topographic Map Series. This series consists primarily of standard quadrangle maps made from original field and photogrammetric surveys, but also includes a variety of special maps.

The standard map series includes quadrangles bounded either by $7 \frac{1}{2}$ minutes of latitude and longitude (map scale of 1:24,000), or by 15 minutes of latitude and longitude (map scale of 1:62,500). All topographic surveys, except for Alaska, are made to the accuracy standards of the $1: 24,000$ scale. In rural or wilderness areas the first publication is sometimes at the $1: 62,500$ scale rather than $1: 24,000$. In addition to the quadrangle maps of the 71 -minute and 15 -minute series, the National Topographic Map Series includes maps of the United States, the individual States, metropolitan areas, national parks, and quadrangle maps covering the country at $1: 250,000$ and $1: 1,000,000$ scale. Most of these special series are compiled from standard quadrangle maps and other source material. Each individual series is intended to fulfill a specific type of map requirement.

Because manmade and natural features change with industrial development, expansion of metropolitan areas, the building of new highways, and other activities, revision and maintenance of existing maps are carried on under a continuing program. 


\section{THE GEOLOGICAL SURVEY}

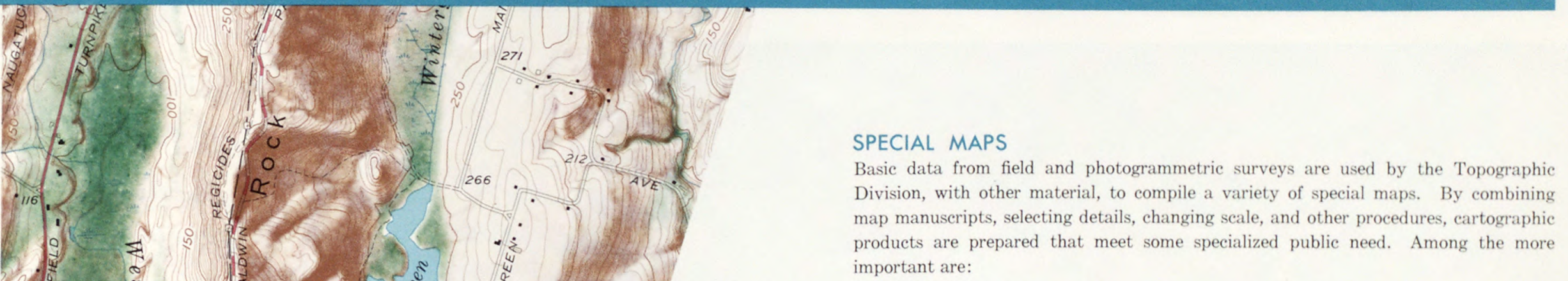
important are:

\section{STATE MAPS}

Compiled at a scale of 8 miles to the inch, State maps are published for general administrative planning and for use as base maps. For each State three editions are usually prepared: a planimetric base map, a highway map with contours, and an edition with relief shown by shading.

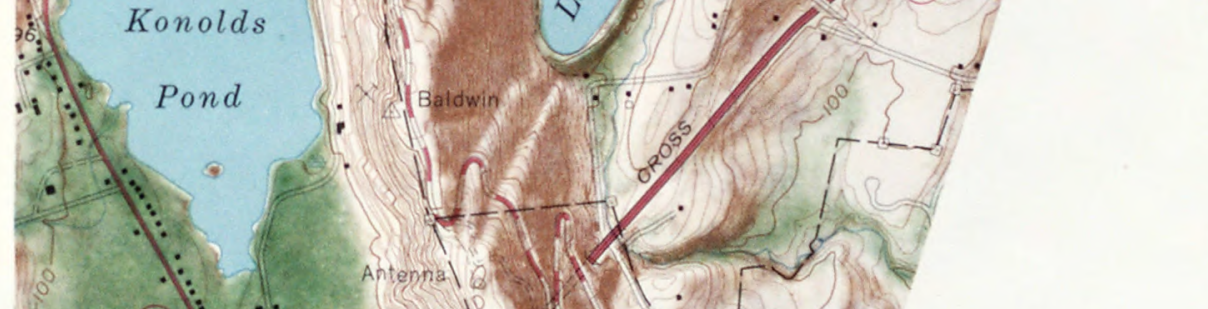

\section{METROPOLITAN AREA MAPS}

Maps of major cities and their surrounding areas are prepared by combining two or more standard $7 \frac{1}{2}$-minute quadrangles. The New York City map covers an area of nearly 1,600 square miles and is made up of 32 quadrangles.

\section{NATIONAL PARK MAPS}

For the millions of Americans who enjoy outdoor recreation, the Survey prepares topographic maps of the national parks, monuments, and other areas maintained by the National Park Service. Like metropolitan area maps, these are frequently made by combining $7 \frac{1}{2}$-minute quadrangles into a single map sheet. 


\section{A FORECAST FOR THE FUTURE}

THE LONG-RANGE MAPPING PROGRAM

Responsibility for exploring and developing the Nation's resources is shared by many organizations, both public and private. Among them, however, the Geological Survey has the chief responsibility for surveying and mapping the land surface-mapping that is a prerequisite to efficient development. The objectives of the Topographic Division long-range program are: (1) to produce, publish, and distribute quadrangle maps of the National Series; (2) to revise and maintain all maps of the National Series; $(3)$ to produce related maps and other publications as necessary in the national interest; and (4) to improve products, operational techniques, and instrumental equipment-mainly through research and development.

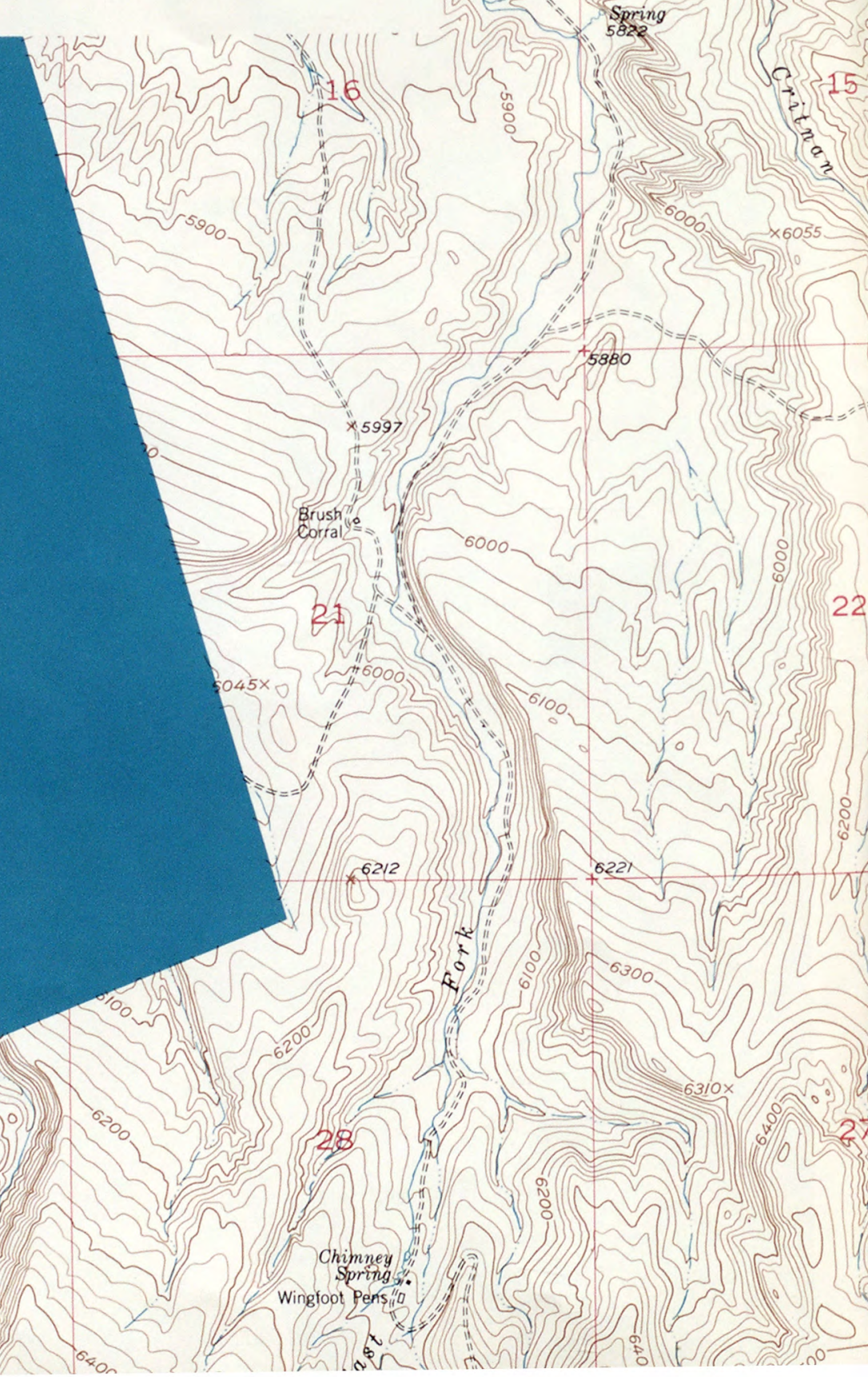




\section{OF MAPPING}

The Topographic Division has long been a leader in putting ideas into reality - developing improved equipment, perfecting mapping methods and techniques, improving map format and symbolization, and designing completely integrated mapping systems.

New developments in instrumentation and techniques have completely revolutionized the mapping operation. Precise aerial photography, the science of electronics, computer technology, and ingenious photogrammetric plotting equip- ment have opened a new era in mapping . . . making it practical to produce quality maps in the air-conditioned comfort of an office.

The Division maintains a modern and well-equipped research center in McLean, Va., staffed by a team of engineers, scientists, technicians, and craftsmen. Members of this research team hold many patents and have been honored for their contributions by professional organizations and technical societies.

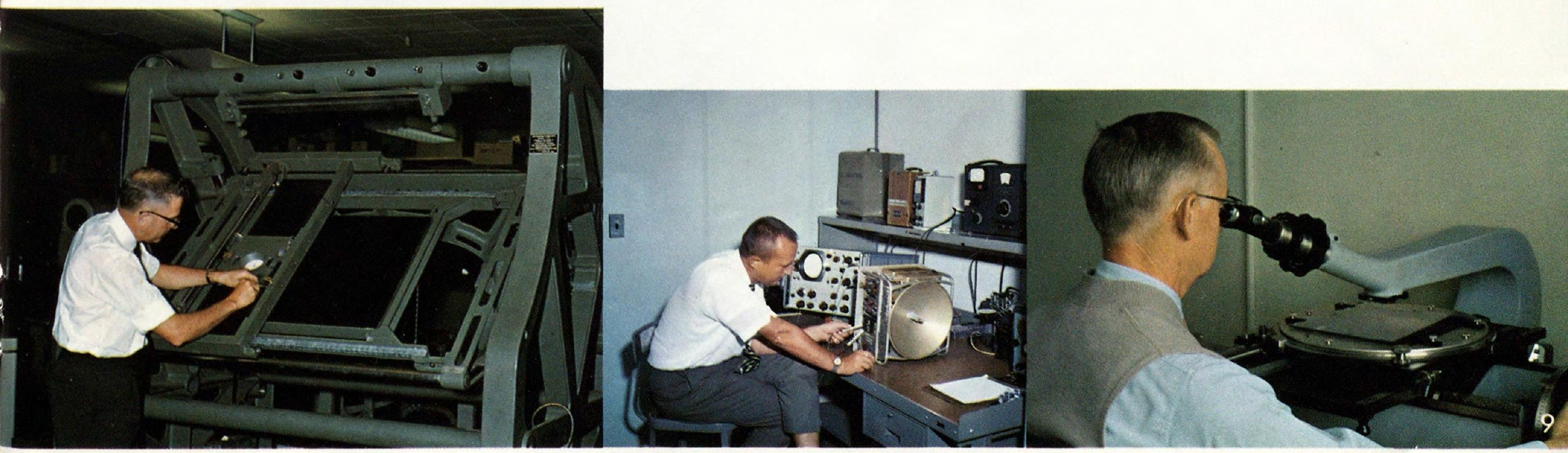




\section{INSTRUMENTATION}

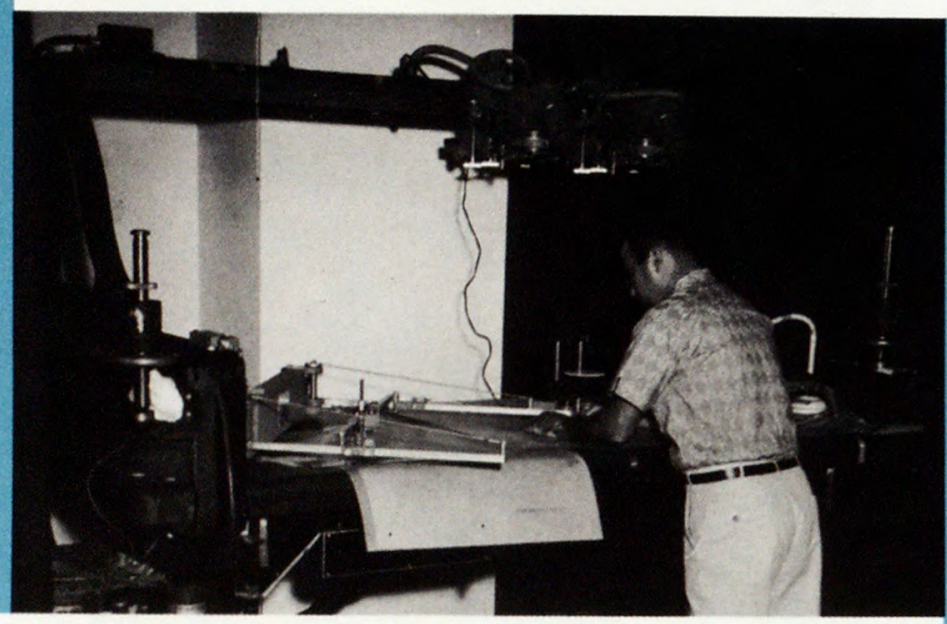

Among the instruments shown here, the Orthophotoscope provides the practical means of producing uniform-scale aerial photographs-photographs on which distances, directions, and areas may be accurately measured. Their wealth of detailed information, in true position, makes such photographs a valuable tool for geologists, foresters, and others concerned with the earth sciences.

Complex instruments-optical, mechanical, electronicare the heart of modern mapping systems. Topographic Division engineers have designed and developed many of the instruments that have revolutionized mapping and surveying in the Geological Survey and in the mapping profession, in this country and throughout the world. 
Helicopters and electronic distance-measuring instruments are combined in a system of establishing mapping control in rough difficult country.

\section{RESEARCH IN ELECTRONIC HORIZONTAL CONTROL} In the Airborne Control (ABC) system, the helicopter serves as an observing platform, as a mobile target, and as transportation for the field engineers. A Hoversight permits the pilot to hover at a measured distance directly above the point for which a geodetic position is desired. Ground parties at points of known position simultaneously determine distances and directions to the hovering helicopter. When observations are completed, the helicopter moves to the next position, and the procedure is repeated.

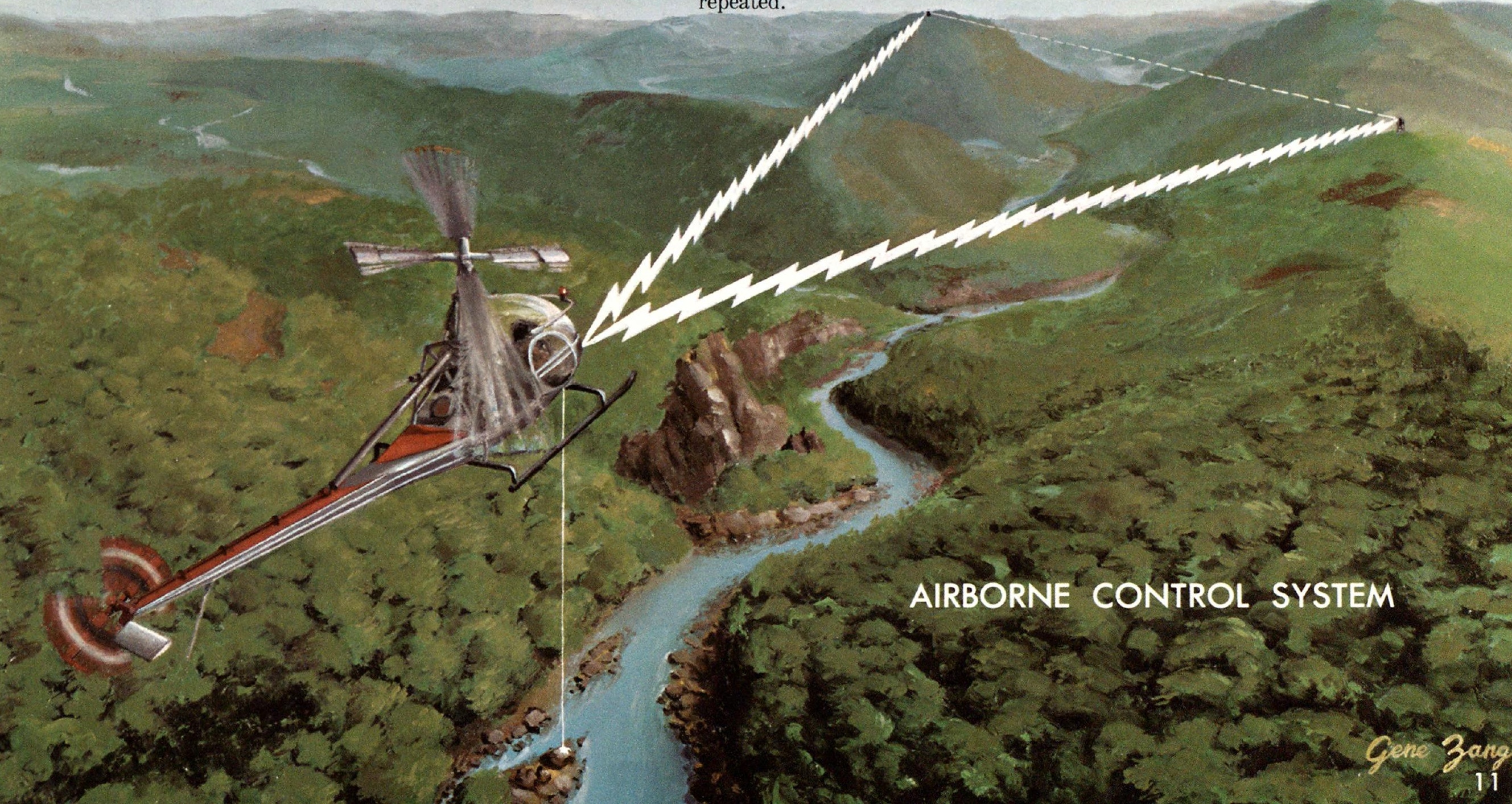




\section{RESEARCH ON ANALYTICAL AEROTRIANGULATION}
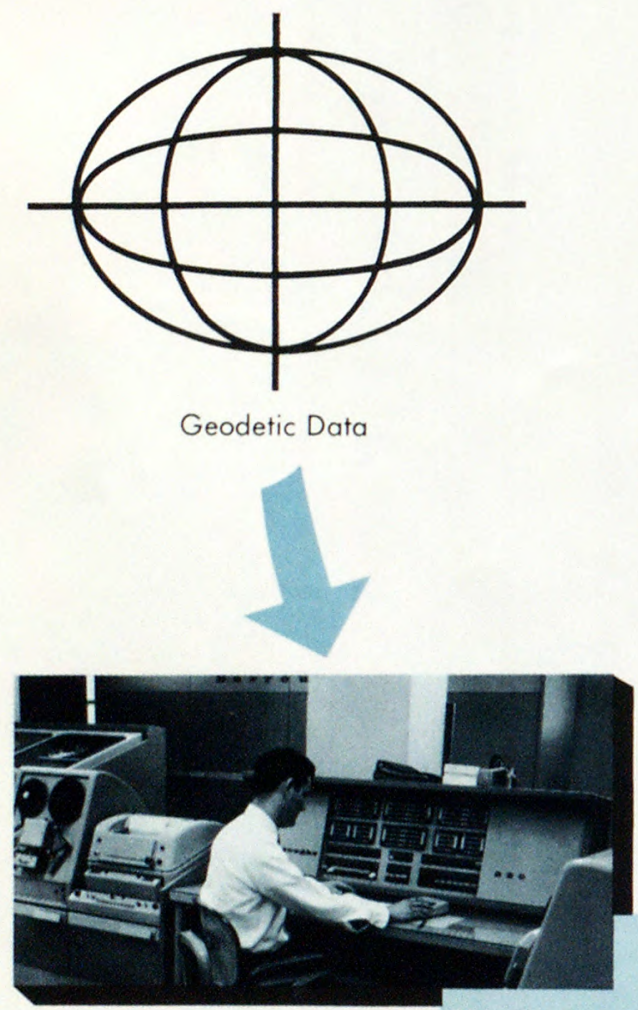

Electronic Computer



Automatic Coordinate Plotter

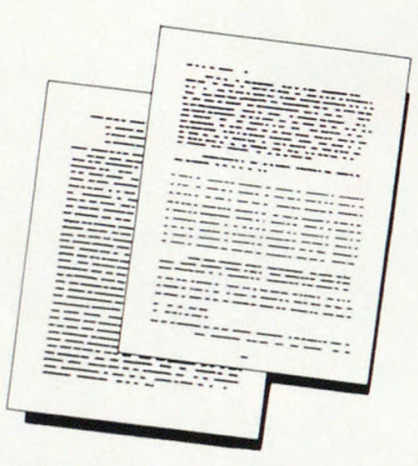

Photogrammetric Principles
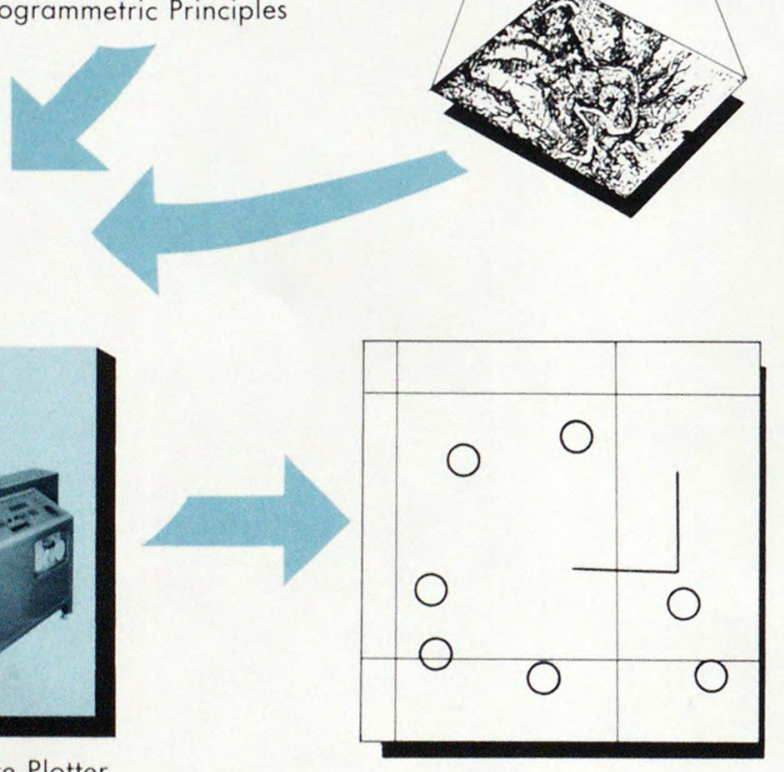

Base Sheet

(containing horizontal and vertical control)
A key factor in the economy and accuracy of photogrammetric mapping is the unique ability to extend the relatively sparse field control to provide adequate control for map compilation. The Topographic Division has under development a purely analytical and automatized system for establishing photogrammetric control points, whereby highspeed electronic computers are used to solve mathematical equations. The photocoordinates of control image points are observed on a precise comparator and these coordinates, along with geodetic and other pertinent data, comprise the input for computing the horizontal positions and elevations of the control points. 


\section{RESEARCH IN GRAPHIC EXPRESSION}

Spectacular technological advances are all meaningless if the finished map cannot be easily read and understood. Improved map design-improvements to the present topographic map series or new concepts in map representationis part of a continuing effort to produce better, more useful maps. Improvements in map legibility, utility, and appearance may be achieved through better feature symbolization, better format, better color balance, and improved map lettering.
An exciting prospect of a new concept of cartographic representation is the direct use of photoimagery. A new photographic process enhances the more significant detail on aerial photographs, while subduing the background tones. This technique emphasizes the edges as they appear in the aerial photographs and in effect shows features by line images. The resulting prints resemble a map. Enhanced photoimagery may be useful as a map substitute or as symbol patterns for certain types of map features.

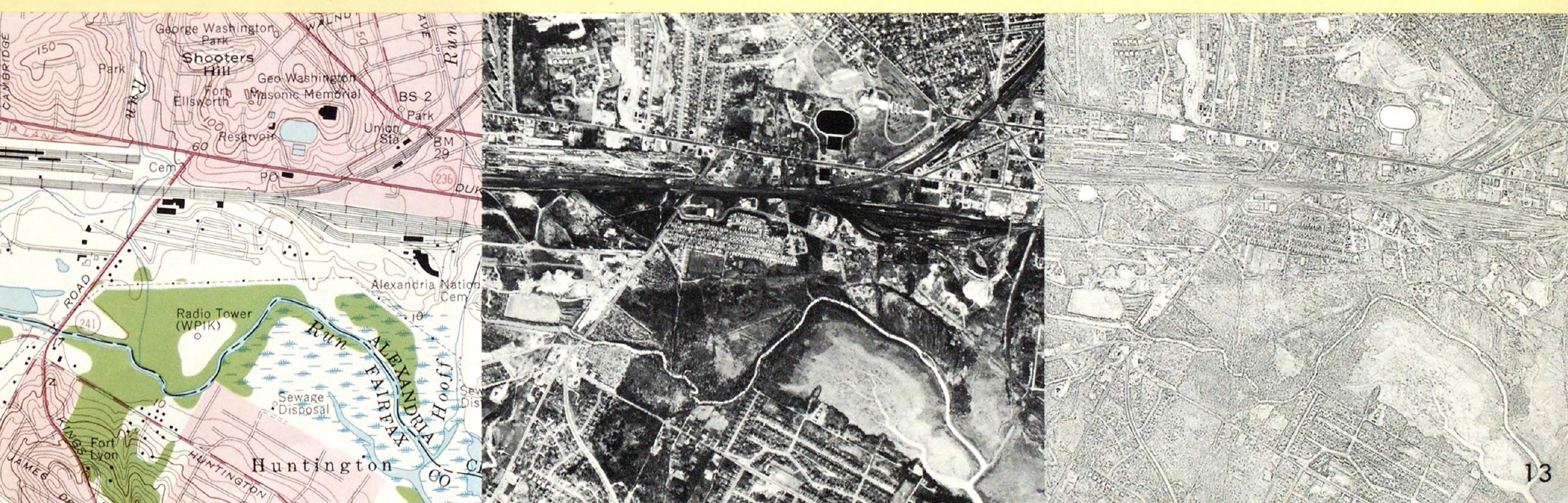




$$
\mathbb{L}
$$




\section{SELECTING HIGHWAY ROUTES}

In planning modern highways, topographic maps save millions of dollars by eliminating costly and time-consuming preliminary surveys. The terrain character, drainage, interconnections, obstacles, and other considerations influencing the route choice are shown in true relationship on topographic maps. 


\section{SELECTING INDUSTRIAL SITES}

Choice of an industrial site may depend on transportation facilities, water and power supplies, commuting convenience of employees, and other factors, in addition to the building plot itself. Topographic maps present a large part of this information in graphic form.

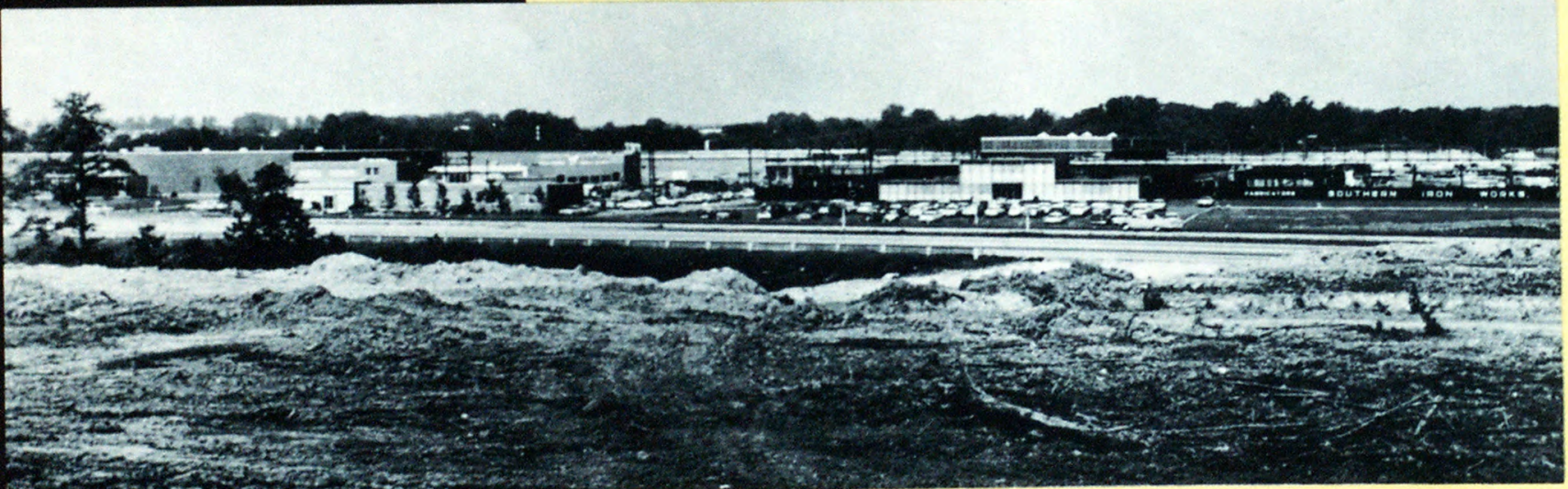




\section{BASIC TOPOGRAPHY ......}

\section{THE FOUNDATION}

FOR

\section{SPECIALIZED MAPPING}

Specialized mapping-such as the geologic mapping shown here-starts with a foundation of accurate, detailed topography. Many kinds of special-purpose maps are based on generalpurpose topographic maps. 


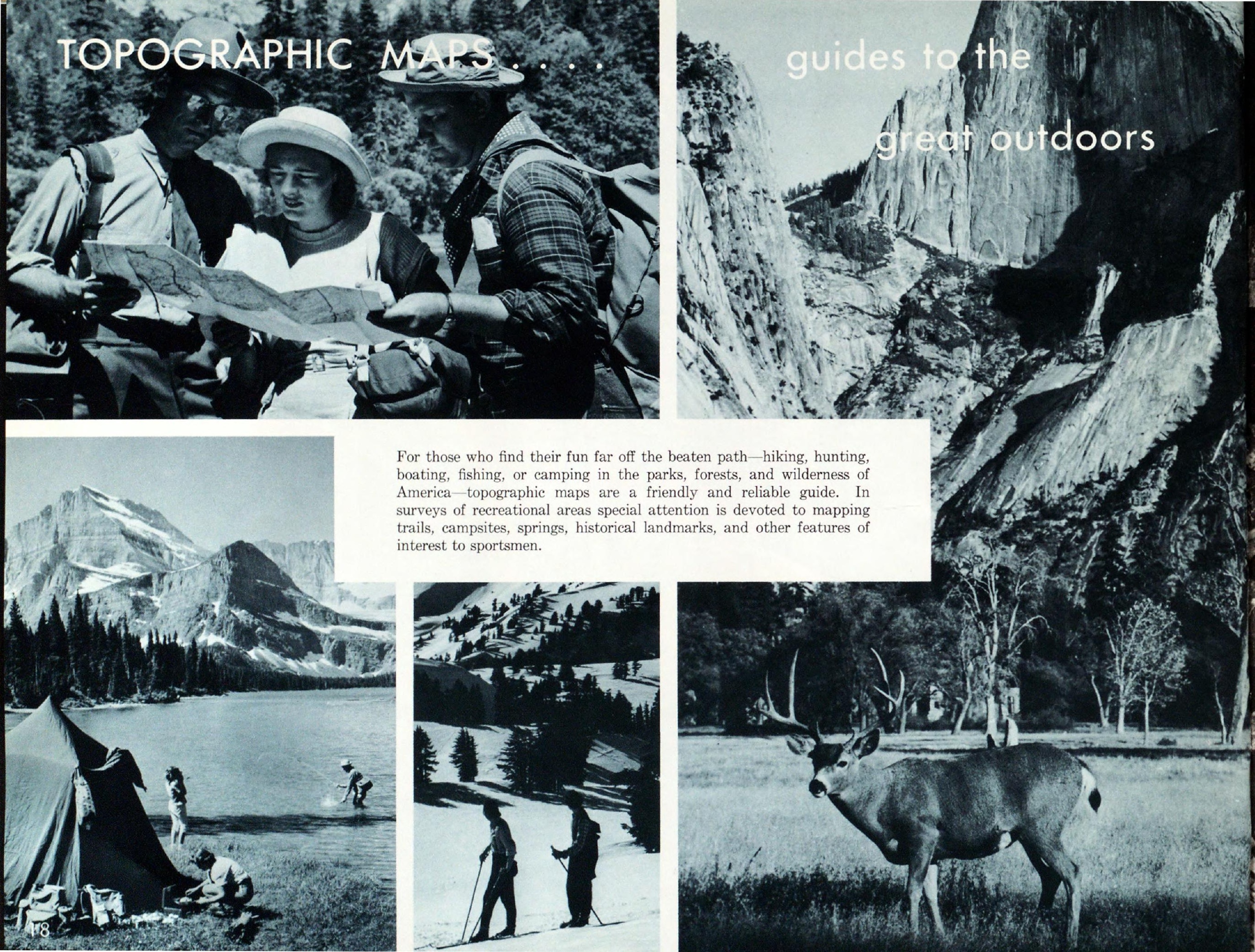




\section{TOPOGRAPHIC MAPS}

\section{are used to select AIRPORT SITES}

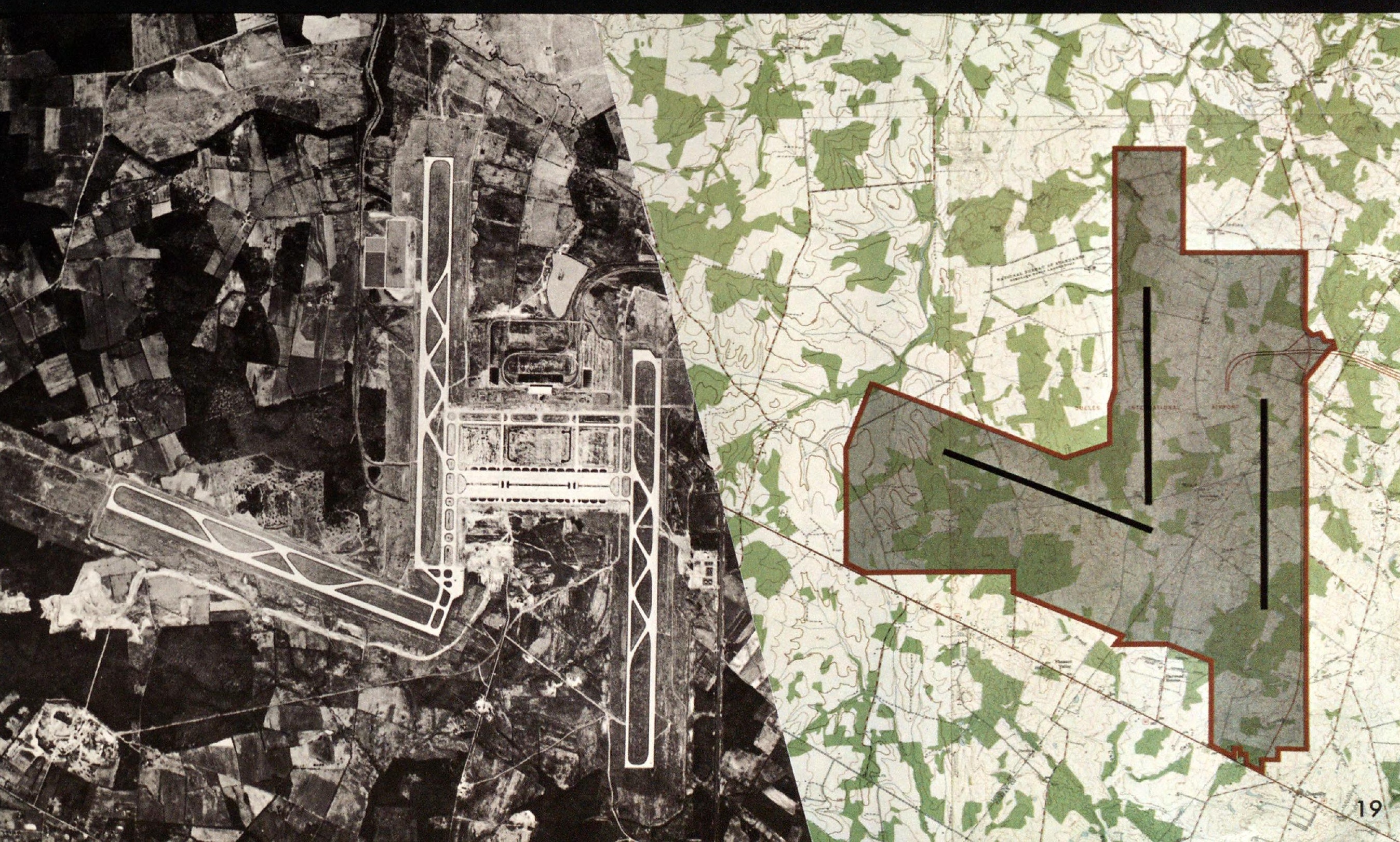




\section{SELECTING RADIO TELESCOPE SITES}



This huge radio telescope is set in a natural bowl near Arecibo, Puerto Rico. A depression of suitable shape and size was found by studying topographic maps.

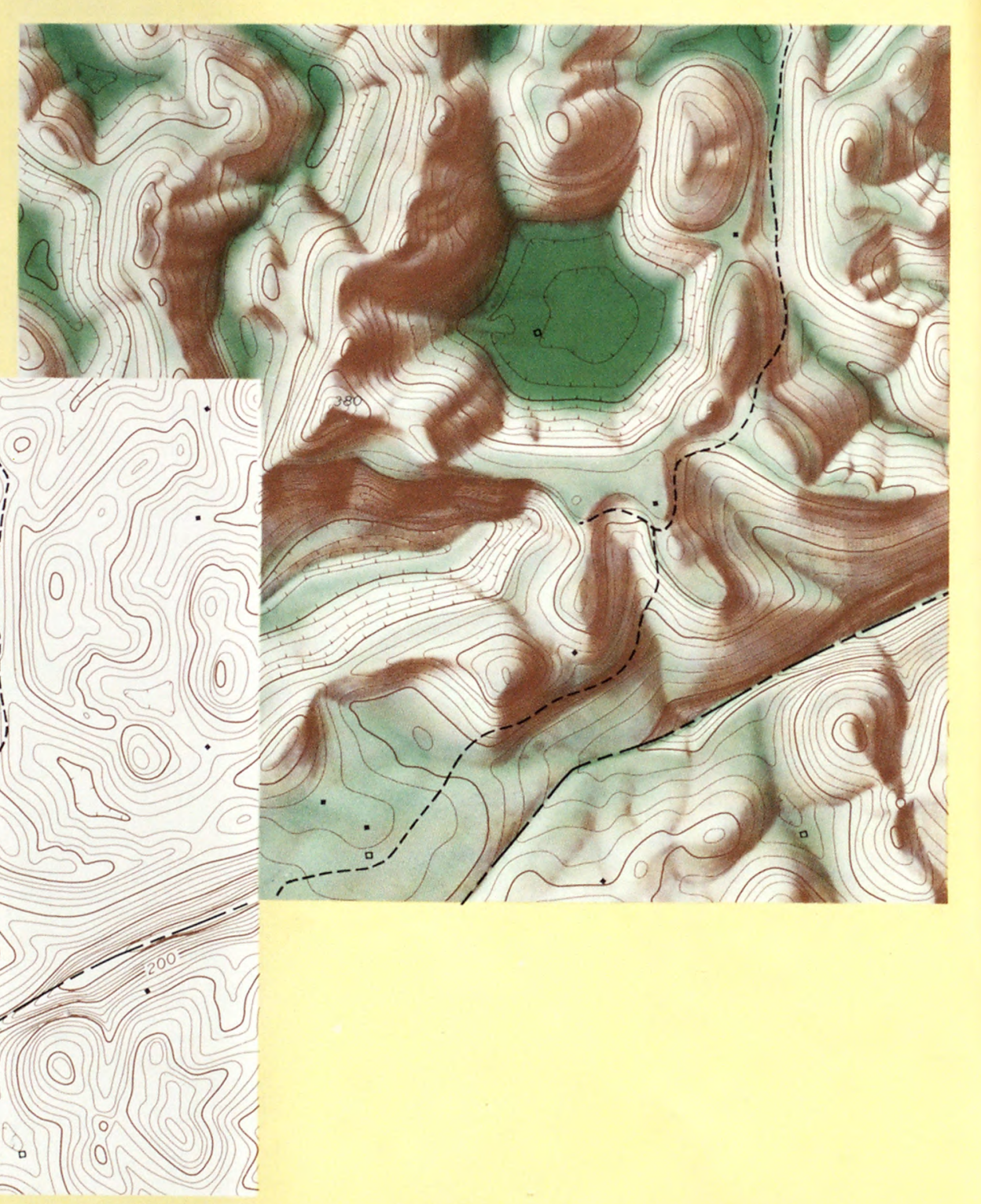


Modern topographic mapping is a highly complex operation . . . organized into specialized field and office phases, each incorporating the most modern equipment and techniques. People skilled in many fields - administrative, supervisory, engineering, scientific, and technical—work together as a team.





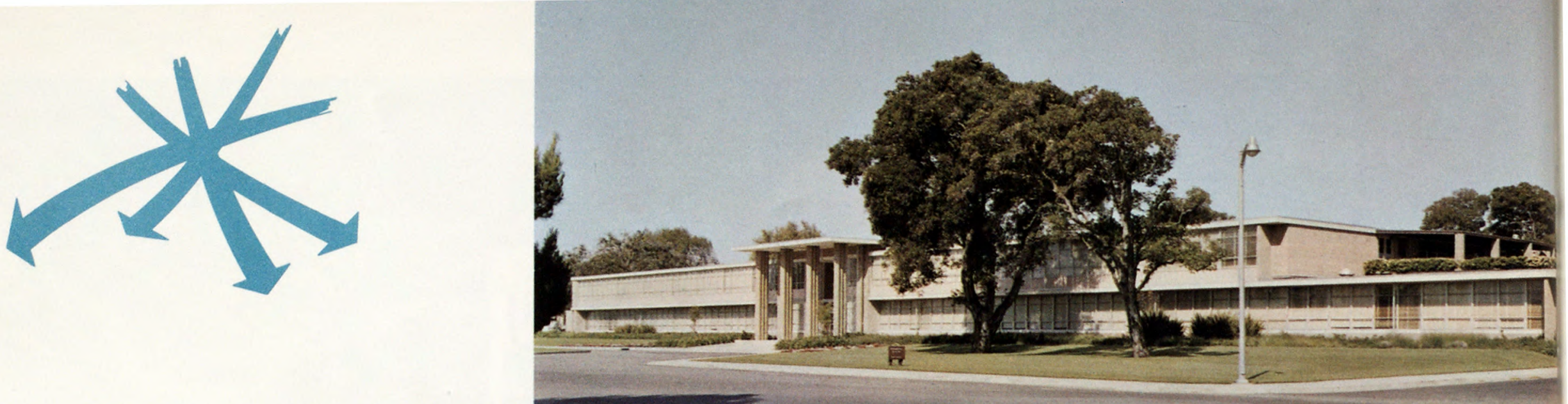

\section{WIDE DIVERSITY OF LOCATION}

Topographic Division employees enjoy unequaled diversity in work location. Those attracted to the great outdoors may be assigned a challenging project in the majestic high mountain country - or perhaps a less strenuous but equally rewarding assignment near some great metropolitan center. Others who prefer a more settled community life may work at one of the Division's headquarters offices. Whatever the assignment or location, each new project represents a new challenge-for no two mapping projects are exactly alike nor do they present the same problems. Topographic mapping is unique in this respect.

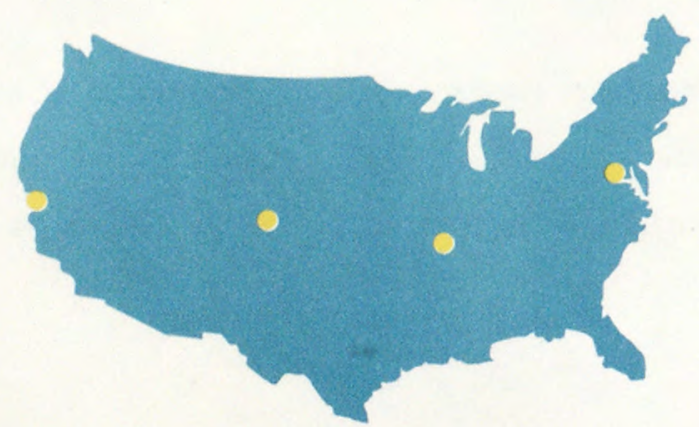

Topographic mapping operations of the Geological Survey are divided into four geographical Areas-each with a centrally located headquarters office-

Atlantic Area at Arlington, Va.

Central Area at Rolla, Mo.

Rocky Mountain Area at Denver, Colo.

Pacific Area at Menlo Park, Calif.

The Topographic Division also maintains an administrative staff in Washington, D.C., a research center in McLean, Va., and an office for special maps in Silver Spring, Md. Each area is essentially a complete mapping organization-managed and staffed by professional people - supported by highly skilled technicians and well- staffed clerical offices and fully equipped to perform all the mapmaking operations, planning, training, and operational research required to carry out the mapping program. 


\section{ASSIGNMENTS OVERSEAS}

Topographic Division engineers who enjoy travel and adventure may also be assigned to projects in Samoa, Puerto Rico, the Virgin Islands, or Antaretica-all within the Division's mapping responsibility. Smallscale mapping by the Survey in Antarctica is part of the research program of the National Science Foundation.
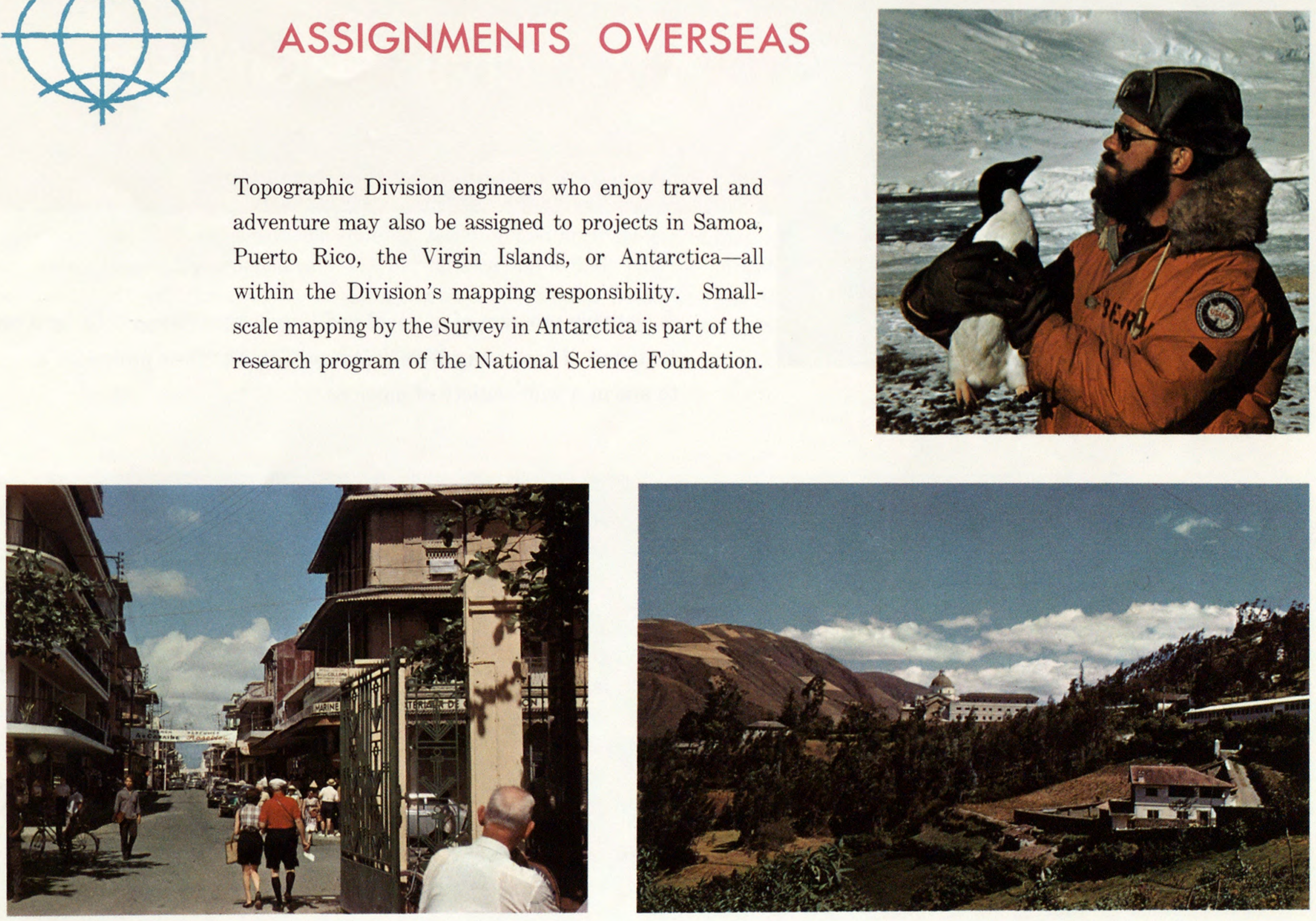


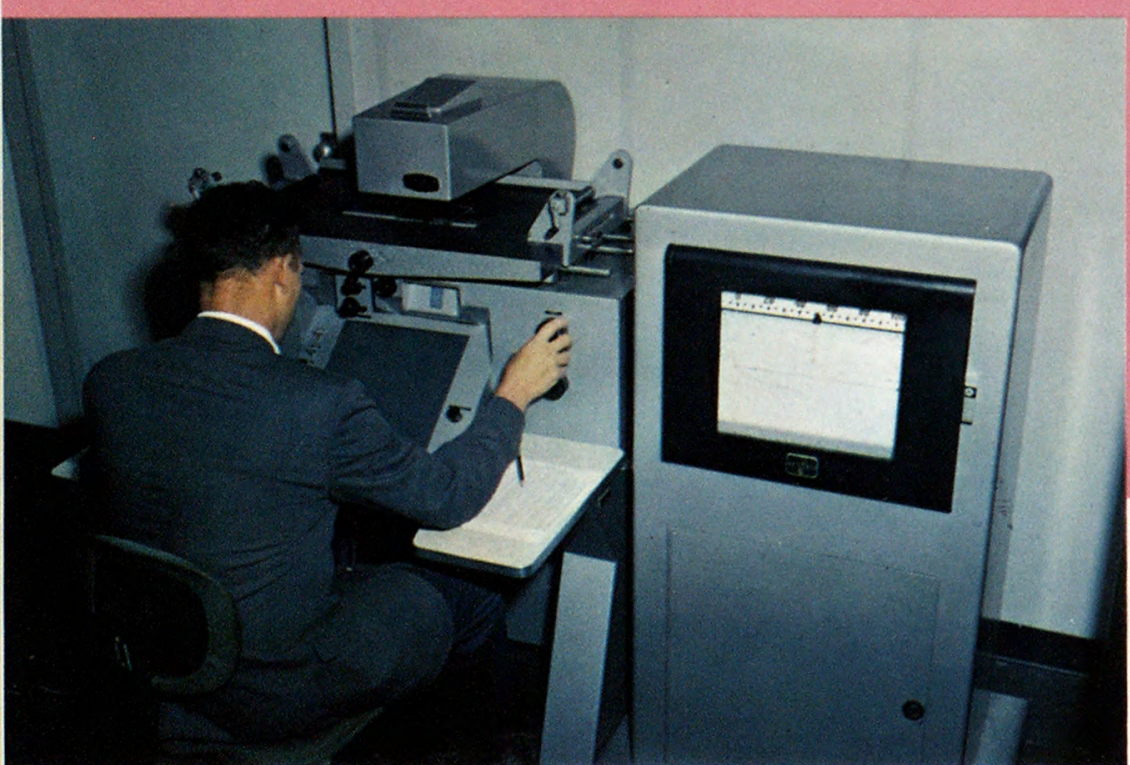

\section{OPPORTUNITIES FOR}

\section{CIVIL ENGINEERS}

A mapping program of national and international scope calls for a competent staff of career engineers-men dedicated to their profession and eager to accept a wide variety of missions.

To assure that men have this capacity, the Topographic Division carries on a program for the professional development of graduate civil engineers. Over a period of several years, instruction by means of lectures, study assignments, and practical experience is given in all phases of topographic mapping operations. In addition to a thorough knowledge of both theory and practice, the training develops qualities of leadership - the ability to inspire and direct others.
Career engineers are the key men in the Topographic Division organization-in administration, in programing, in operations and in research. Basic engineering knowledge and skills are applied in many ways depending on the aptitude of the man. Career engineers must have a broad background in the technology of topographic mapping, and be able and willing to work on a variety of problems.

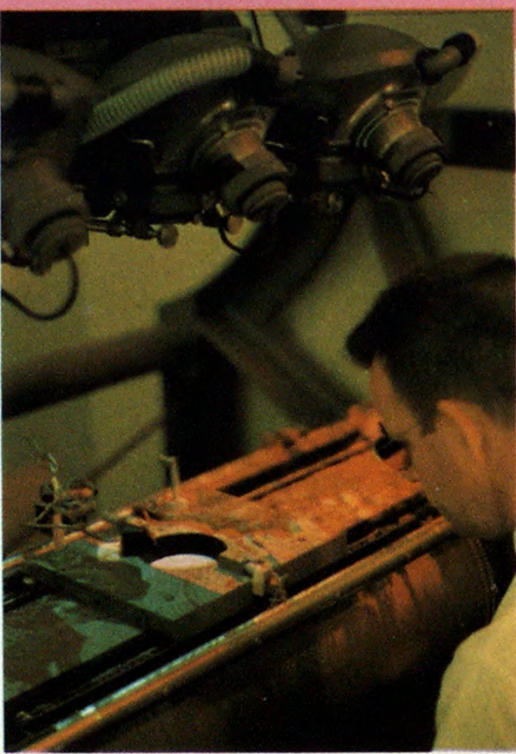




\section{OPPORTUNITIES FOR CARTOGRAPHERS}

Cartographers in the Topographic Division are responsible for the graphic representation of map features in published form. They edit and check map materials, and direct the finishing operations required to prepare manuscript maps for multicolor printing. These operations include color-separation scribing, selection and arrangement of map lettering, and various assembly procedures. The appearance and legibility of the published map depend largely on the skill of the cartographers. For those possessing the ability to apply artistic and engineering principles to improving map design or map processing, cartography is a challenging field of endeavor.
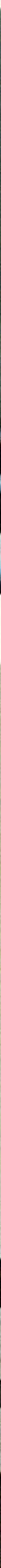


\section{OPPORTUNITIES FOR THE TECHNICIAN}

- CIVIL ENGINEERING

- CARTOGRAPHY
- MECHANICAL ENGINEERING

- PHOTOGRAPHY
Topographic Division technicians work in direct support of engineers and cartographers-members of production teams. They perform many functional tasks requiring highly specialized abilities. Although professional training is not required, technicians enjoy many of the same advantagesrecognition, travel, supplemental training, a wide choice of assignments and locations. Technicians may advance as high as their talents will allow.
Technician jobs are available in many interesting specialities in topographic mapping-field surveys, map compilation, color-separation scribing, instrument design, drafting, instrument repair, computer programing, photographic processing, and others.

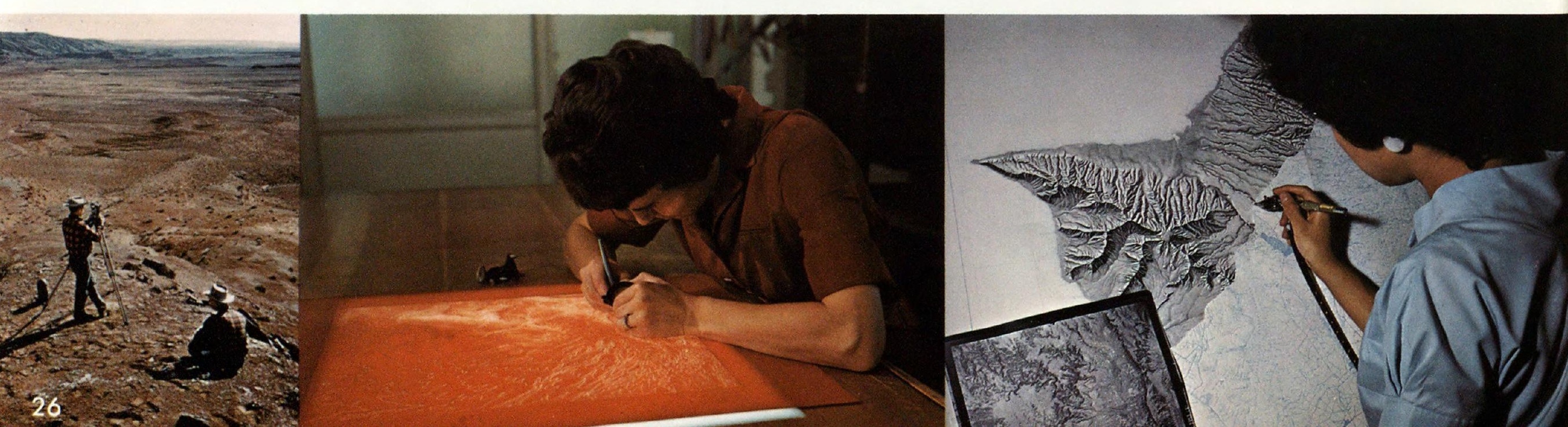




\section{OPERATIONAL}

\section{IN THE FIELD}

Field training emphasizes new instruments and techniques that have radically changed survey practices. Notable among these developments are electronic distance-measuring equipment, electronic equipment for measuring difference in elevation, the application of electronic computers, self-leveling instruments, and the expanded use of helicopters to facilitate the transportation of men and equipment.

Training in field operations consists of a series of field assignments in varied terrain. Trainees become thoroughly familiar with all types of field surveys--triangulation, traverse, leveling, planetable mapping, to mention a few--and learn how to operate and care for the instruments and equipment used. They study administrative procedures in preparing reports and hiring seasonal field employees, and learn how to make the necessary contacts with local residents.

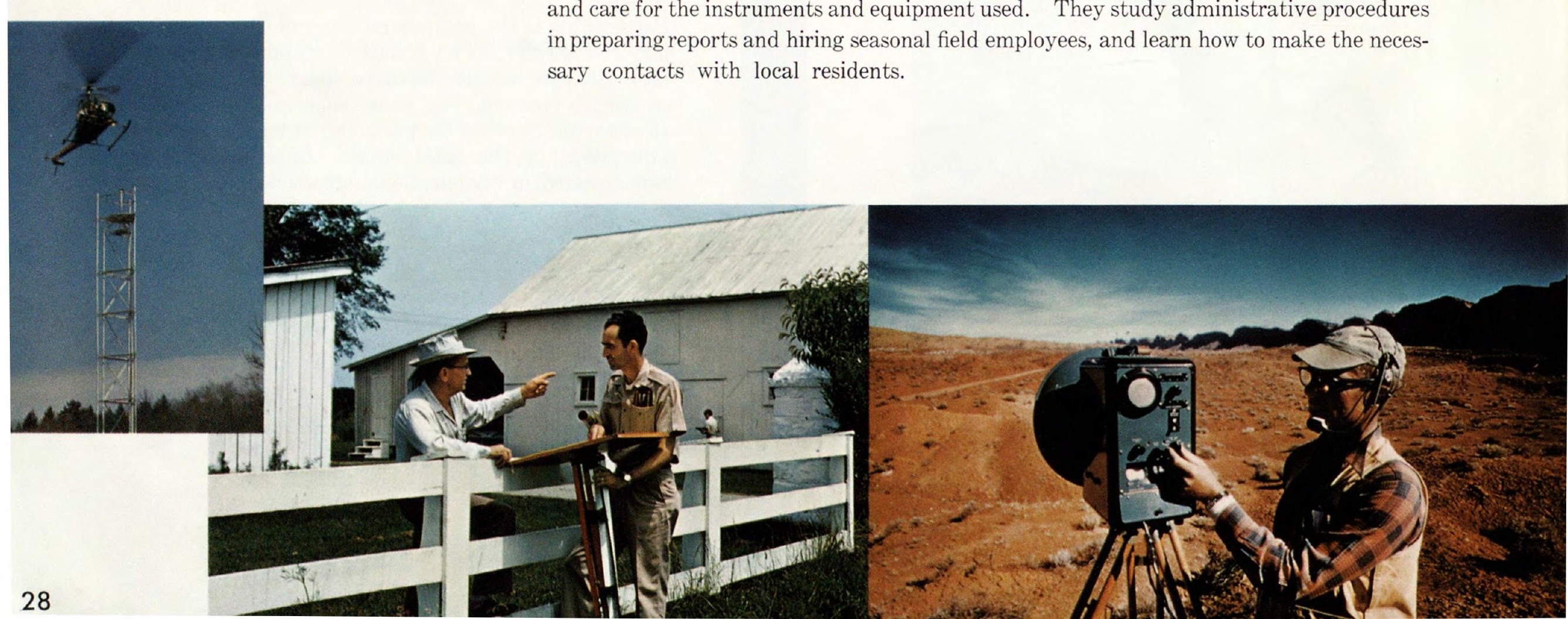




\section{TRAINING}

\section{IN THE OFFICE}

Trainees are instructed in each of the many office operations required . . . planning and scheduling projects into the mapping program, planning and procuring aerial photography, engineering aspects of geodesy and its practical application to mapping, photogrammetric techniques for map compilation, and various map-finishing operations.

Trainees are taught basic photogrammetric theory and application of this theory in mapping. They learn how the map framework is developed, office techniques for extending field control to satisfy photogrammetric mapping requirements, and the actual map compilation using different types of stereoplotting equipment.

Trainees are given an intensive indoctrination in various map-finishing operations so they will understand reproduction requirements and be able to take them into account in their future work.
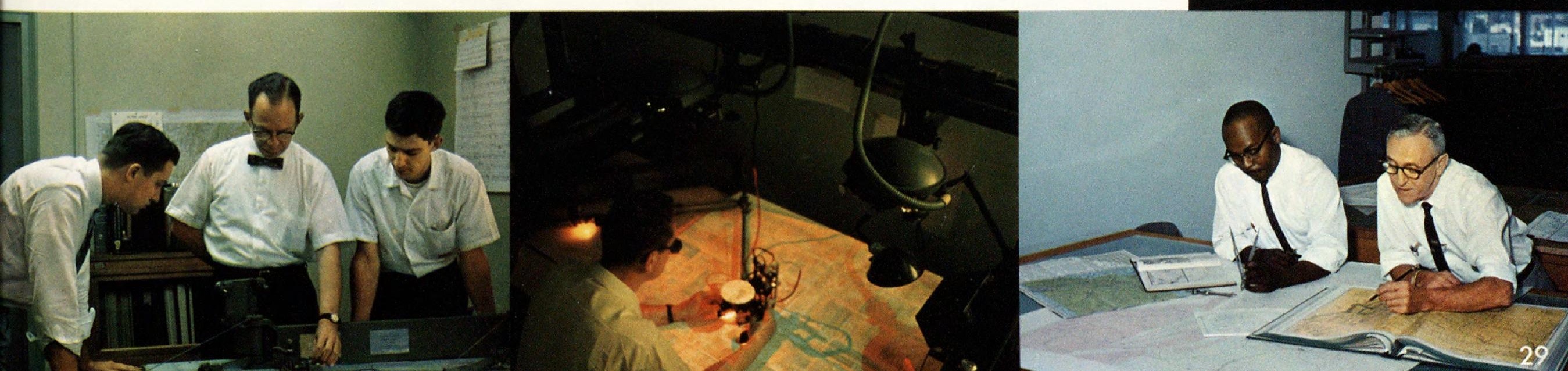


\section{STUDENT TRAINEE PROGRAMS}

The Topographic Division offers summer on-the-job training to undergraduate civil engineers and to high school graduates who have been accepted in a college of engineering. Such practical experience sandwiched between academic studies has many advantages. Immediate use of college studies tends to make them more meaningful. Summer employment provides direction--helps the student to select courses that best fulfill his needs--perhaps even to choose a profession.

Practical experience helps the student to mature earlier and faster--to mold his professional attitude and personal charactera chance to test his performance. Summer employment gives identity with an established organization-provides the student with a sense of belonging-of purpose. Such training also provides access to expensive and complex equipment not readily available at school.

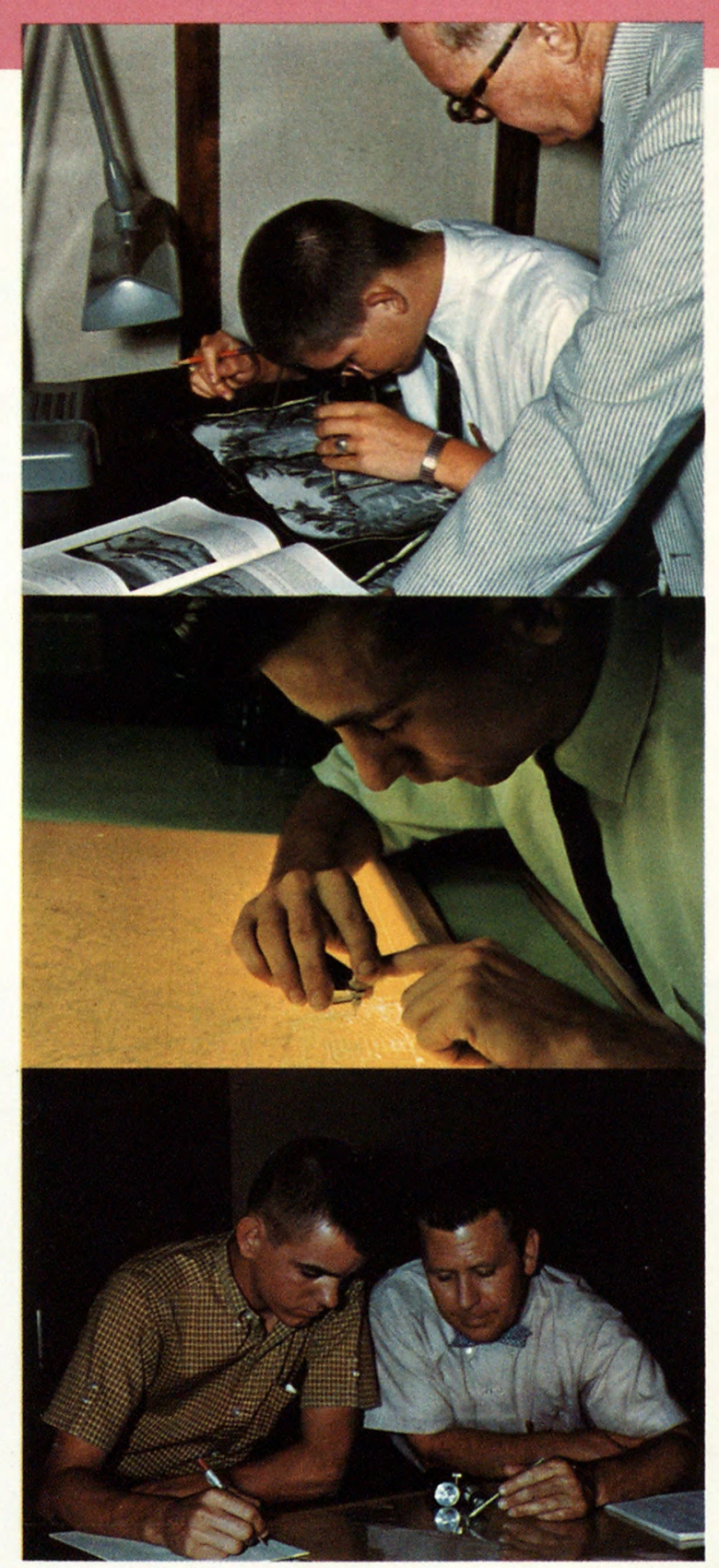




\section{with the TOPOGRAPHIC DIVISION •..}

Ask your College Placement Officer to arrange an appointment for you to meet a U.S. Geological Survey Topographic Division representative-Or direct your inquiry to any of these Topographic Division mapping centers:

Atlantic Region Engineer U.S. Geological Survey 1109 North Highland Street Arlington, Virginia 22200

Central Region Engineer U.S. Geological Survey Box 133

Rolla, Missouri 65401
Rocky Mountain Region Engineer

U.S. Geological Survey

Federal Center, Bldg. 25

Denver, Colorado 80225

Pacific Region Engineer

U.S. Geological Survey

345 Middlefield Road

Menlo Park, California 94025

Chief Topographic Engineer

U.S. Geological Survey

Washington, D.C. 20242 
